\title{
Cree Youth Engagement in Health Planning
}

\author{
Nickoo Merati, McGill University \\ Jonathan Salsberg, University of Limerick \\ Joey Saganash, Cree Board of Health and Social Services of James Bay \\ Joshua Iserhoff, Eenou Eeyou Community Foundation \\ Kaitlynn Hester Moses, Cree Nation Government \\ Susan Law, Trillium Health Partners - Institute for Better Health, University of Toronto \\ Indigenous communities experience a greater burden of ill health than all other communities in \\ Canada. Across the Eeyou Istchee territory of northern Quebec, all nine James Bay Cree \\ communities experience similar health challenges. In 2014, the Cree Health Board (CHB) \\ supported an initiative to stimulate local community prioritization for health change. While many \\ challenges identified were specific to youth (10-29 years of age), youth's perspectives in these \\ reports to date have been limited. We sought to understand how Cree youth perceived youth \\ health and their engagement in health and health planning across Eeyou Istchee. As part of a \\ CHB-McGill partnership, this qualitative descriptive study adopted a community-based \\ participatory research approach. Cree community partners recruited ten Cree youth to participate \\ in two focus groups, and five Cree youth coordinators to participate in key informant interviews. \\ Thematic analysis was conducted and inductive codes were grouped into themes. Cree \\ participants characterized youth engagement into the following levels: participation in \\ community and recreational activities; membership in youth councils at the local and regional \\ levels; and, in decision-making as planners of health-related initiatives. Cree youth \\ recommended greater use of social media, youth assemblies, and youth planners to strengthen \\ their engagement and youth health in the region. Our findings revealed an interconnectedness \\ between youth health and youth engagement; Cree youth described how they need to be engaged \\ to be healthy and need to be healthy to be engaged. Cree participants contributed novel and \\ practical insights to engage Indigenous youth in health planning across Canada.
}

Keywords: Indigenous, youth, health engagement, community-based, participatory research, health planning

\section{Glossary}

For the purposes of this manuscript, the following terms are defined as below.

Eeyou Istchee (in Cree, meaning the "Cree Peoples Land"): The territory corresponding to the regional authority of the Cree Nation Government. This region is composed of nine Cree Nation communities, including: Chisasibi, Eastmain, Mistissini, Nemaska, OujéBougoumou, Waskaganish, Waswanipi, Wemindji, and Whapmagoostui.

Cree Nation Government: Represents the administrative arm of the Grand Council of the Crees (the highest political body representing the Cree). It is responsible towards environmental protection, the hunting, fishing and trapping regime, economic and community development, the Board of Compensation, and other matters. The Cree Health Board, an independent entity created through the James Bay and Northern Quebec Agreement, sits as observers when issues related to its mandate are discussed.

\section{Cree Board of Health and Social Services of James Bay, hereafter referred to as Cree} Health Board (CHB): Entity responsible for the administration of health and social services 
for all persons residing either permanently or temporarily in Region 18, the administrative region of the Ministry of Health and Social Services of Quebec corresponding to the Cree territory of James Bay. In partnership with the Government of Québec, the CHB provides health and social services to the nine communities of the Cree Nation in Eeyou Istchee (Cree Board of Health and Social Services of James Bay, 2012).

Miyupimaatisiiun: An all-encompassing Cree word for a global concept of health that can be loosely translated as "being alive well". Miyupimaatisiiun encompasses physical, mental, emotional and spiritual wellness: it implies a way of living that allows one to care for their family, enjoy life and participate in their community, and be sufficiently strong to be able to hunt in the frigid conditions of the North (Cree Board of Health and Social Services of James Bay, 2004).

Iiyuu Ahtaawin Miyupimaatisiiun Planning (IAMP) Team: In the Cree language, 'Iiyuu Ahtaawin' means 'Cree community' and Miyupimaatisiiun is defined as above. The IAMP initiative is a community-based and community-driven wellness planning process involving Eeyou Istchee's local and regional entities and groups. The IAMP Team as defined in this paper as the team of individuals responsible for the evaluation of the IAMP initiative, composed of seven CHB members (both Cree and non-Cree) and four McGill researchers (non-Cree).

Youth: A self-identified label, but also corresponding to the ages of 10 to 29 as defined by the CHB.

Youth coordinator: A Cree person who is actively involved in leading and planning youth activities and engagement opportunities, either locally in their community, or regionally across Eeyou Istchee. Youth coordinator may not be this individual's formal position or sole role in the community, but they serve as key informants regarding the structures that exist for youth to engage across Eeyou Istchee.

Youth council member: A Cree youth member who sits on either a local or regional youth council, and represents the youth and youth needs in their corresponding community or communities.

\section{Acknowledgements}

I express gratitude towards every Cree person who took the time to share their voice, realities, and spaces with me, with special thanks to the Nemaska community who welcomed me to their land and traditions. I would like to thank our McGill and Cree Board of Health and Social Services of James Bay partners who provided necessary contextual and cultural training and data collection support. I acknowledge financial support received from the CIHR Partnerships for Health System Improvement Grant, Faculty of Medicine Internal Studentship, Institute for Health and Social Policy, CIHR Travel Awards, and the Department of Family Medicine. Finally, I would like to extend acknowledgement to the amazing Eeyou and Eenou youth - to those who have lived on the land, and to those who currently live on the land. I am in awe of those that I had the pleasure of meeting and am impressed by the cultural strength and pride that they each carry. I look forward to continue hearing about the inspiring strides that Cree youth will lead. 


\section{Introduction}

Indigenous communities experience a greater burden of ill health than all other communities in Canada (Adelson, 2005). Social determinants of Indigenous health including systemic racism have been associated with unfair differences in power, resources, capacities and opportunities, which lead to a considerable range of health disparities (Paradies, 2018). Peoples in Northern and remote areas face particular challenges with mental health, obesity, diabetes, substance abuse, and maternal or child health issues, with poorer health outcomes and barriers in healthcare resource access (Ford et al., 2012; National Collaborating Centre for Aboriginal Health, 2009, 2013; Young \& Chatwood, 2017).

In the Eeyou Istchee territory of Northern Quebec, all nine Cree communities experience similar health challenges (Cree Board of Health and Social Services of James Bay, 2015b). While the Cree report longer life expectancies and lower infant mortality rates than other Indigenous populations, the Cree are currently overrepresented in diabetes, heart disease and sexually transmitted infections (Cree Board of Health and Social Services of James Bay, 2015b). Moreover, the Cree conceptualization of health is distinguished from a Western biomedical definition with the term Miyupimaatisiiun, best interpreted as "being alive well". Miyupimaatisiiun encompasses physical, mental, emotional, and spiritual wellness: it implies a way of living that allows one to care for their family, enjoy life and participate in their community, and be sufficiently strong to be able to hunt in the frigid conditions up North (Cree Board of Health and Social Services of James Bay, 2004). For the Cree, health implies much more than merely the absence of disease.

In 2014, the Cree Health Board engaged in a major planning effort to align this more holistic notion of health and current service provision through a major community-based planning initiative - the Iiyuu Ahtaawin Miyupimaatisiiun Planning (IAMP) - for all nine Cree communities of the Cree Nation. Funded in part by Health Canada, the IAMP initiative aims to improve planning and outcomes across the region, encouraging communities to lead and create detailed plans for Miyupimaatisiiun. IAMP partnered with McGill researchers in an evaluation of this work using a communitybased participatory research (CBPR) approach.

Notably, many health challenges that the James Bay Cree leadership have prioritized primarily affect youth (10 to 29 years of age, as defined by the CHB). For example, one in five Cree youth gets involved with Cree Youth Protection Services each year, and many of these visits are youth coming in for mental health crises, behaviours associated with alcohol and drugs, or suicide attempts (Cree Board of Health and Social Services of James Bay, 2016). In addition, increases in chronic diseases among youth, and the rate of diabetes and sedentary lifestyles of youth, are identified as healthcare and social issues important to the Cree Nation, and thus need to be addressed (Cree Board of Health and Social Services of James Bay, 2015b).

While many health priorities for change are specific to the youth sector, the IAMP evaluation thus far has not yet formally involved youth to ask them how they have been engaged or how they need to be engaged in health planning. This further corroborates current evidence stressing the absence of youth voice and participation in healthcare research on a global scale (United Nations, 2003). Particularly in the Eeyou Istchee context, half of the James Bay Cree population is under 25 years of age, and about 1 in 5 babies is born to a mother under the age of 20 (Cree Board of Health and 
Social Services of James Bay, 2015a). In order to place the end-user's (youth's) priorities in research, young Cree people must be heard in all steps of the evaluation research and health planning efforts. This investigation aims to better understand how youth perceive health or Miyupimaatisiiun, as well as their past, present, and future engagement in health initiatives in the community. Accordingly, our three interconnected research questions are the following:

1. How are James Bay Cree youth engaged in health-related activities in their communities?

2. How would James Bay Cree youth like to be engaged in youth health planning in Eeyou Istchee?

3. How do James Bay Cree youth view their health in relation to their engagement in health and health planning?

\section{Methods}

\section{Context}

Nemaska has a total population of approximately 851 in 2017 (Cree Board of Health and Social Services of James Bay, 2015-2016). Youth make up nearly half the total population in Nemaska (Figure 1).

\section{Figure 1}

\section{Population Pie Chart of Nemaska}

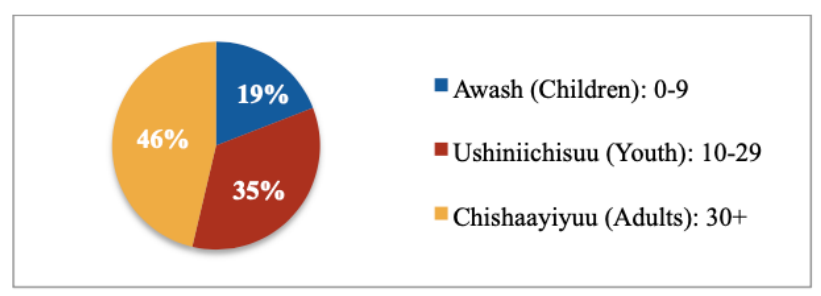

\section{Research Approach}

Community-based participatory research (CBPR) falls under the umbrella of participatory research as it involves all members of the project in key aspects of the research process, including the (1) identification of the research topic, (2) interpretation of the results, and (3) diffusion and dissemination of the findings (Israel et al., 2001).

Key characteristics of CBPR and how they align with the aims of this research are outlined in Appendix A.

\section{Methodology}

\section{Research design}

We used a qualitative descriptive study design as described by Sandelowski (2000) to gain an in-depth understanding of youths' and youth leaders' perspectives, and to access the emotional and motivational components of their lived experiences (Curry et al., 2009; Sandelowski, 2000). Qualitative descriptive designs stay close to the surface of the data and are ideal when full descriptions of phenomena are desired (Sandelowski, 2000).

\section{Data collection}

All data collection was guided by our Cree CHB and community school partners. Purposeful, snowball sampling was employed (Patton, 1990).

Two semi-structured youth focus groups were conducted with a total of 10 Cree youth participants, ranging from 15 to 17 years of age. The objectives of these focus groups were to identify key themes that represent youth health and health priorities, as well as how youth engage in their communities. Focus groups were led in collaboration with community leaders and were held at the local community school. As recommended by our Cree partners, groups were mixed gender and age since this was how youth were comfortable in their peer groups. Focus groups lasted approximately 50 minutes and were audio-recorded and 
transcribed. In accordance with our CBPR approach, focus groups were co-facilitated by a community youth leader and the primary author. Focus group guides were modified by our Cree partners.

Five key informant interviews were conducted with Cree community members who were involved with youth and youth health engagement and planning; these leaders worked in and represented either the regional- or community-level. The objective of these interviews was to better understand how youth health services are planned and the existing structures that exist for youth engagement in the community. Interviews lasted approximately 60 to 75 minutes and were audio-recorded and transcribed.

\section{Data analysis and validation}

Thematic Analysis was used to identify, analyze, and report themes within the focus group and interview transcripts (Glaser \& Strauss, 1999), where emergent codes were in turn grouped into overarching themes (Lofland \& Lofland, 1995). Themes were defined as important patterned responses or meanings from the text as they related to our research questions (Braun \& Clarke, 2006). Analysis was recursive and conducted by the first author with virtual coding from the co-supervisors. Preliminary results were presented to and validated by two representatives of the $\mathrm{CHB}$, one community representative, and one youth participant. In addition, regular meetings, phone calls, and text messages were used as debriefing strategies throughout the process, to ensure rigour with respect to the Cree context and to honour Cree ways of knowledge.

\section{Relationship}

This project built upon an existing partnership between McGill researchers and the CHB. Techniques used in accordance with Salsberg et al.'s strategies for a successful participatory research process (Salsberg et al., 2015) are delineated in Appendix B.

\section{Results}

\section{Youth "Engagement" Revisited} Prior to discussing Cree youth engagement, it is important to characterize how youth viewed and defined youth engagement. While there was no one agreed upon framework, participants generally defined youth engagement as a spectrum.

The first level of youth engagement was defined as participation, where youth showed up and partook in an activity or attended an event. The second level of youth engagement was defined as youth council membership, where youth were nominated to represent the youth voice and were often solicited by decision-makers. The third and highest level of youth engagement spectrum described was youth engaged as planners, where youth were the decision-makers and led in planning towards action. These categories are illustrated in Figure 2.

\section{Figure 2}

\section{Spectrum of Cree Youth Engagement}

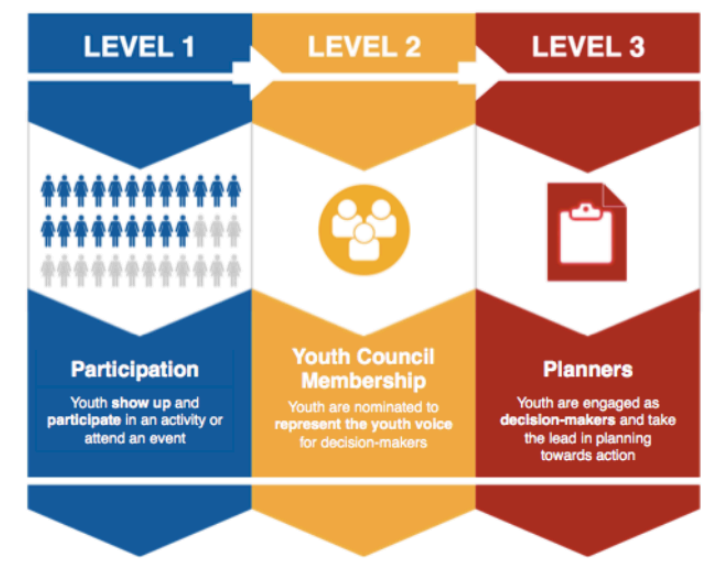

\section{Perspectives on Current Levels of Youth Engagement}

In general, participants described

high levels of Level 1: Participation and 
Level 2: Youth Council Membership engagement in their communities, with pride. Participants shared divergent feelings, however, regarding the extent to which youth are engaged as Level 3: Planners. They described how adult planners often ask for the 'youth voice' when making decisions (e.g., the Youth Grand Chief being included in the major Cree Nation Government meetings).

In these examples, adult planners are "asking" the youth for their opinions - in other words, it is still not the youth who are the health planners. This leaves room for potential disconnect between youth voice and youth action. Indeed, some youth expressed frustration with decision-makers who listened but did not act:

Participant: “They just listen. I don't know...

Facilitators: Are there things you've recommended that haven't been acted on?

Participant: Mhm.

Facilitator: So how can youth voices best turn into action?

Participant: Guess we have to wait till we're adults."

Youth participants highlighted how a lack of action can impact youth's trust: "You must be listening to the youth and what they're saying, and show you are taking action. So, when the youth see that, that's when they'll be more interested... to trust their leaders, or the councils, or the coordinators".

\section{Future Youth Engagement Towards Health Action}

For better youth engagement that leads to health action, youth and youth coordinators underscored the importance of the following themes:

\section{Allowing Youth to be Health Planners}

Participants highlighted the importance of opportunities for youth to plan and engage at the highest level in health initiatives. Participants discussed an array of benefits that arise when youth lead as listed below.

Utilizing role modelling for other youth to engage. Repeatedly, participants underscored the importance of role modelling in Cree youth culture, and how youth can inspire other youth towards more healthy behaviours. One youth coordinator observed how younger youth model off older youth in the gym:

\section{"I've seen kind of younger kids coming in, ages 12 to 15 , trying out the 5- pounders. I guess trying to do the same as the older teenagers, going to the fitness... they wanna try that too..."}

One youth put it simply: "If youth see other youth leading the activities or the programs, it will definitely get their attention".

\section{Builds on pre-existing trust} between youth. One youth council member felt that it was important for a youth to not only lead initiatives, but create a more trusting environment for other participating youth:
"I lead and participate in [activities]. Like I join them, so they can feel comfortable to join as well. It takes a while for a youth to get comfortable...I welcome them...I talk to [youth], and am a friend to them."

That said, it is worthy to mention that deference and shyness was noted by participants to be an important part of this community's Cree culture. The use of social media and particularly Facebook was highlighted as helpful in this regard, making it easier to reach shy youth who are less likely to engage in person: 
"Facebook is a big tool for our youth because, there are youth that don't speak and are very shy. So, they have Facebook and their own world, so they read through that... and maybe you can't reach them in person at school, but you'll be able to reach them alone in their room..."

\section{Longevity of youth engagement} when youth lead. Youth coordinators are actively engaged in planning and decisionmaking for different youth programs in their communities. Notably, all youth coordinators who participated in this study were also former youth council members and had been working with and for youth for quite some time:

"What motivates me... there's so much... I guess I could say I have this channel, this desire to be a part of making change. From my experience when I was young, I guess I could say I was pretty observant - 'How come nobody's doing this'... It started to develop into: 'You know what, somebody needs to do something. I'm somebody. Alright - I'll do it."'

Furthermore, one youth participant described how having youth as planners and leaders can increase the relevance and longevity of the program to truly address youth health needs:

"Having the youth involved in the planning part, I think that would be helpful. Youth know what [youth] want and what they need, or what they're interested in. And it will definitely boost up the whole planning part."

Finally, one youth coordinator highlighted the importance of youth sitting in on decision-making boards for their futures:

"When we have our big meetings... yes they're 18, but we can still welcome them. Cause they're gonna be sitting up there in a few years."

\section{Better promotion and uptake of} health programs: One youth coordinator proposed the creation of a youth promoter to advertise and promote services, which could better program success and trust:

"A [youth] can explain to them, you know, healthy living ways and not being doubtful of the Cree Health Board and the services offered,... its services would be a little more utilized and understood, and trusted...there is a lot more outreach to be done"

Finally, one youth coordinator described how testimonials from youth who have participated could inspire other youth to engage:

"I hope these individuals inspire the others. I mean yeah, [a previous participant] was telling me how much better she was feeling, but it doesn't necessarily mean that everybody knows it... reporting back or getting that feedback out there, I'd like to do that more."

\section{Appropriate evaluation of youth engagement and health programs}

Youth spoke about the difficulties they encounter when coordinators and planners want greater youth engagement; specifically, how planners often use youth attendance rates and numbers as indicators of a program's success. One youth described how a program that was meaningful to them was terminated on the basis of low 
attendance, and how this could be problematic when program numbers overshadow positive experiences:

"There used to be an art program, I really enjoyed that program, but it stopped... because of the lack of numbers. I understand it has to do with the budget and all that, but what if those, let's say, 5 youth participants had a rough week, and going to that activity or program could change their mindset? Like they could have had motivation to do more, be more..."

Indeed, certain youth coordinators illustrated the importance that they placed on numbers to indicate an event's success:

"I'm coming from a coordinator's perspective. You always wanna have, to be honest, double or triple the amount of participants that you have."

\section{Interconnectedness between youth health and youth engagement}

Given that youth's conceptualizations of health or Miyupimaatisiiun (see Glossary) influences how they view their engagement in and planning of health activities, understanding their conceptions of health was essential.

\section{Youth Need to be Healthy to be Engaged}

Many community youth engagement opportunities and activities required an application process, where healthy behaviour (such as sobriety) was a prerequisite. When asked why these rules were in place, one youth explained how traditional hunting activities require mental and physical strength:

"You have to be quiet to hunt. You have to be patient to hunt. You have to be smart too. You have to be strong. You have to go places a lot, you have to walk, and sometimes there may be snow or grass, big trees, lakes...”

Other youth spoke to the fact that health requirements could serve as stepping stones towards long-term change:

"They're trying to make the youth healthy you know... If you think you can go one week without drugs or alcohol, it makes you think you can continue."

Youth also raised the notion that one person cannot fully engage and help others and the land before they help themselves:

“...If you want to engage and take care of our land and people, we need to take care of ourselves first... it sounds conceited, but still."

\section{Youth Need to be Engaged to be Healthy}

Participation in community activities was fundamental to youth wellbeing, as expressed by one youth participant:

"Being back in the bush... without service or wifi... disconnected from some people, but connected with other people. You're being active everyday... it's probably a good thing."

Moreover, participating in community gatherings was important for the social dimension of youth health:

"When people gather together, there's a lot of laughter and smiles. Everybody's having a great time. And doing that is also beneficial for the individual youth's health. Cause you never know when somebody's having a bad day or something, and they come to these [community] events and they feel better after." 
Beyond participation, opportunities to engage by planning activities were also described as essential to supporting youth health. Youth illustrated how leading cultural activities can connect them to their tradition and health:

"It's a way of life in the Cree region: walking, spending time in the bush, learning about medicine in the bush, leading more Cree-based cultural activities... that also can connect with healthy living"

Being given opportunities to lead and plan can also help increase confidence and positive self-esteem for some, as one youth council member highlighted:

"When I got involved... it really boosted up my confidence in leading activities. I suggest that youth get involved with these activities. Like, let them do the work. Let them plan... so they can have the opportunity to lead and break their bubble."

\section{Limitations}

As an external non-Cree person, there are limitations to what the primary author was able to understand and interpret; the validation process was essential to ensure our Cree partners identified with what is presented in this work. Partnership and extensive review of materials from three Cree partners (one of which is a youth), the primary author's eight-day immersion in the community, as well as co-leading the focus groups with a community youth leader, were all important to this end.

This study focused on a limited number of youth and youth coordinators from one community, hence intra- and intercommunity differences may be masked. These results are still valuable and potentially transferable to other communities and youth in similar contexts.

Finally, the qualitative descriptive study design allowed for a deep, contextual understanding of the perspectives of a small number of relatively informed youth aged 15-17 years old, which also may not be generalizable to other ages or settings. We believe, however, that contextualized understanding is most valuable to local communities and policy makers.

\section{Discussion}

Much of the published literature on youth health lacks actual voices from youth themselves. In collaboration with the $\mathrm{CHB}$ and Cree community members, including youth, we explored ways in which youth and youth coordinators describe Cree youth engagement in the community, on councils, and in health decision-making, suggestions for the future, and how youth engagement and youth health are intertwined.

The levels of youth engagement according to the spectrum of participation, youth council membership, and planners, as outlined in Figure 2, were characterized. While positive towards youth engagement as health planners, a few Cree youth expressed dissatisfaction about decision-makers who listened but did not act. One youth stated that they simply needed to wait until they were older to be taken seriously in planning decisions. Participants also described how the disconnect between youth voices and action could improve if decision-makers understood the importance of building good relationships in this context - how being a friend could build trust and foster an understanding of youth needs, and how when one youth leads, their friends tend to follow. Program leaders' age was also considered a potential hierarchal factor in engagement. Issues of hierarchy in engaging youth have been previously characterized, especially with "high-risk" youth, and the 
associated dynamics of power (Iwasaki et al., 2016). The importance of informal role modelling for Cree youth was also described as an integral aspect of Cree teachings, as recognized in other Indigenous cultures (Klinck et al., 2005). The benefits of good role modelling and mentoring to promote positive health behaviours in youth can also fall under the connectedness factor of Indigenous Peoples' health and wellbeing (Reilly et al., 2008).

Ultimately, a few participants spoke to a need for greater and more genuine youth engagement as health planners. This finding is congruent with the literature where most engagement is described in the youth council member capacity, and youth voices are solicited to bring to (presumably) adult health planners (Genuis et al., 2015). That said, our participants highlighted the sustainability and longevity of youth engagement when they were given the chance to lead. The intrinsic spark and motivations that youth felt they always had in order to create change was noted as continuing into adulthood. Participants described how youth leaders could help a program last longer by accurately identifying underlying issues and leading programs promoting for greater youth retention. This action agrees with previous studies on the importance of engaging Indigenous youth as planners in their own research, as they are best suited to identify, understand, and interpret their own health challenges (Clark et al., 2013; Genuis et al., 2015). Sustainability of projects under Indigenous youth leadership could also be explained by Jagosh et al.'s (2012) finding that a transfer of ownership often takes place when, through participatory research approaches, those who are directly involved in the program or its results lead the program itself (Jagosh et al., 2012). Finally, participants also expressed how youth engaged as health planners was good practice, since youth ultimately fill these positions in the future; similarly, the youth in Blanchet-Cohen's (2011) study advocated for communities to view youth engagement as a benefit to the whole community and future investment (Blanchet-Cohen et al., 2011).

In order to better engage youth in the future, social media strategies, particularly Facebook, were noted as important. The importance of these media in Indigenous youth engagement has not been highlighted by many previous youth engagement studies, which appear to focus more on artsbased and peer-to-peer mentorship methods. However, our participants highlighted Facebook as an important tool to solicit and advertise to youth, and particularly reach marginalized youth. Indeed, the fact that our youth focus groups were held in collaboration with the community school implies that youth who participated were already attending school; youth who are not in school, young parents, youth who are less involved, or youth who are dealing with addictions were likely not reached in this study - a challenge acknowledged in previous publications (Iwasaki, 2015). Hence, social media could be a valuable tool for service providers to consider, especially when reaching out to more marginalized youth.

One explicit finding of this study was the interconnectedness between Cree youth health and their engagement, and how one was needed for the other. Youth participants highlighted the importance of helping oneself before being able to engage and help others and the land, even though, as one participant described, prioritizing yourself could be interpreted as conceited. The importance of working on oneself was echoed throughout this study and may suggest a fundamental Cree value. Furthermore, this finding could be related to 
the influence of role modelling in Cree teachings as described.

In addition, youth described how they needed to be physically and mentally well, and abide by the required sobriety rules to partake in traditional activities. Youth participants also shared the potential long-term benefits of sobriety prerequisites. Taken together, these results underline Cree youth's strong desires to engage in cultural activities, perhaps enough to give up unhealthy behaviours. Considering the aforementioned interconnectedness, this health behavioural change could either be a cause or consequence of youth engagement.

Participants also described how engagement opportunities could lead to better health. The positive effects of Indigenous youth participating in sports and physical activities can be related to the wellcharacterized ability of physical activity to strengthen youth resilience and development (Bruner et al., 2016). Youth participants also shared how their engagement helped increase their self-confidence, and one youth shared how youth councils helped them break out of their shell. This finding agrees with previous Indigenous youth literature that links youth engagement with increased social skills and pride (Clark et al., 2013; Crooks et al., 2010) and permitting their true selves to come out (Stewart et al., 2008). In addition, engagement opportunities allowed youth to foster the social component of their wellbeing. Being engaged in traditional activities, away from technology, with their families and communities, and immersed in Cree ways of living, were the components of traditional activity participation that youth attributed to their feeling healthy and well. This is congruent with Blanchet-Cohen's (2011) finding that the impact of gatherings on Indigenous youth cannot be quantified, and it is the less tangible aspects of this social dimension that affect youth wellbeing (Blanchet-Cohen et al., 2011).
The quantification of youth health ties well into our participants' opinions on the quantification and evaluation of youth participation. This was a notable point of divergence between some youth and youth coordinator participants. One youth coordinator recommended the use of testimonials in their health programs to allow youth to share their sentiments and inspire other youth. Testimonials are a form of qualitative evaluation that could offer meaningful feedback for youth coordinators and financial decision-makers when planning for youth programs, so long as the feedback comes from participating youth themselves.

One of the primary goals of this research was to provide insights to the $\mathrm{CHB}$ to help inform current and future health plans for youth. Implications for policy, practice and future research as recommended by our Indigenous participants are delineated in Appendix C.

Finally, it should be noted that a marked desire for the community to succeed underscored this entire project, as indicated through cultural pride and strength-based optimism demonstrated by almost every participant. One Cree coordinator and partner shared a reflection worthy of including verbatim:

"[Working with the youth], it's my joy, it's my pleasure. Because I want this community to succeed and to be vibrant. Of course we have our challenges, but you know. There's a lot of people out there that want their community to run well... I know this next generation will make a big splash, like those remarkable achievers from the past."

\section{Conclusion}

This study contributes Cree youth voices to the limited evidence currently available in Canadian research literature, 
offering practical strategies for greater youth engagement for the Cree Nation. This is a novel area of research that highlights the importance and potential for future research in partnership with Cree people of Eeyou Istchee and Indigenous Peoples of similar contexts. As described by the Cree youth in this study: youth need to be healthy to be engaged, and need to be engaged to be healthy.

\section{References}

Adelson, N. (2005). The embodiment of inequity: Health disparities in Aboriginal Canada. Canadian Journal of Public Health, S45-S61. https://doi.org/10.1007/BF03403702

Blanchet-Cohen, N., McMillan, Z., \& Greenwood, M. (2011). Indigenous youth engagement in Canada's health care. Pimatisiwin, 9(1), 87-111. https://www.suicideinfo.ca/wpcontent/uploads/gravity_forms/6191a85f36ce9e20de2e2fa3869197735/2018 /03/Indigenous-Youth-Engagement-inCanada\%E2\%80\%99s-Health-Care_oa.pdf

Braun, V., \& Clarke, V. (2006). Using thematic analysis in psychology. Qualitative Research in Psychology, 3(2), 77-101. https://doi.org/10.1191/1478088706qp063o a

Bruner, M. W., Hillier, S., Baillie, C. P., Lavallee, L. F., Bruner, B. G., Hare, K., Lovelace, R., \& Lévesque, L. (2016). Positive youth development in Aboriginal physical activity and sport: A systematic review. Adolescent Research Review, 1(3), 257-269. https://doi.org/10.1007/s40894015-0021-9

Cargo, M., \& Mercer, S. L. (2008). The value and challenges of participatory research: Strengthening its practice. Annual Review of Public Health, 29, 325-350. https://doi.org/10.1146/annurev.publhealth. 29.091307.083824

Clark, N., Walton, P., Drolet, J., Tribute, T., Jules, G., Main, T., \& Arnouse, M. (2013, Jun). Melq'ilwiye: Coming together intersections of identity, culture, and health for urban Aboriginal youth. The Canadian Journal of Nursing Research, 45(2), 36-57. https://doi.org/10.1177/0844562113045002 08

Cree Board of Health and Social Services of James Bay. (2004). Strategic regional plan to improve health and social services. CBHSSJB. Retrieved 2016.10.02 from http://www.creehealth.org/sites/default/files /CBHSSJB\%20Strategic\%20Regional\%20P lan\%202004-2014.pdf

Cree Board of Health and Social Services of James Bay. (2012). About us. http://www .creehealth.org/about-us

Cree Board of Health and Social Services of James Bay. (2015a). The current and projected Eeyou population. CBHSSJB Retrieved 2016.10.07 from http://www .creehealth.org/sites/default/files /Current\%20and $\% 20$ Projected $\% 20$ Eeyou $\%$ 20Population\%20November\%202015.pdf

Cree Board of Health and Social Services of James Bay. (2015b). Overview of the health of the population of Region 18. Cree Board of Health's Public Health Surveillance System. Retrieved 2016.10.07 from http://www.creehealth.org/surveillancedata/population-health

Cree Board of Health and Social Services of James Bay. (2015-2016). Annual report of the Cree Board of Health and Social Services of James Bay, 2015-2016. https://www.creehealth.org/sites/default/file s/CBHSSJB\%2020152016\%20AR\%20FINAL\%20low\%20res.pd $\mathrm{f}$

Cree Board of Health and Social Services of James Bay. (2016). eHealth Solution: A youth mental health self-referral service. http://www.creehealth.org/news/community -stories/ehealth-solution-youth-mentalhealth-self-referral-service

Crooks, C. V., Chiodo, D., Thomas, D., \& Hughes, R. (2010). Strengths-based programming for First Nations youth in schools: Building engagement through healthy relationships and leadership skills. International Journal of Mental Health and Addiction, 8(2), 160-173. https://doi.org/10.1007/s11469-009-9242-0 
Curry, L. A., Nembhard, I. M., \& Bradley, E. H. (2009). Qualitative and mixed methods provide unique contributions to outcomes research. Circulation, 119(10), 1442-1452. https://doi.org/10.1161/CIRCULATIONAH A.107.742775

Ford, T., Rasmus, S., \& Allen, J. (2012). Being useful: Achieving Indigenous youth involvement in a community-based participatory research project in Alaska. Int J Circumpolar Health, 71(0), 1-7. https://doi.org/10.3402/ijch.v71i0.18413

Genuis, S. K., Willows, N., \& Jardine, C. G. (2015). Partnering with Indigenous student co-researchers: Improving research processes and outcomes. Int J Circumpolar Health, 74, 27838. https://doi.org/10.3402/ijch.v74.27838

Glaser, B. G., \& Strauss, A. L. (1999). Discovery of Grounded Theory. Routledge. https://doi.org/10.4324/9780203793206

Graham, I. D., Logan, J., Harrison, M. B., Straus, S. E., Tetroe, J., Caswell, W., \& Robinson, N. (2006). Lost in knowledge translation: Time for a map? Journal of Continuing Education in the Health Professions, 26(1), 13-24. https://doi.org/10.1002/chp.47

Holkup, P. A., Tripp-Reimer, T., Salois, E. M., \& Weinert, C. (2004, Jul-Sep). Communitybased participatory research: An approach to intervention research with a Native American community. Advances in Nursing Science, 27(3), 162-175. https://doi.org/10.1097/00012272200407000-00002

Israel, B. A., Schulz, A. J., Parker, E. A., \& Becker, A. B. (2001). Community-based participatory research: Policy recommendations for promoting a partnership approach in health research. Education for Health, 14(2), 182-197. https://doi.org/10.1080/1357628011005105 5

Iwasaki, Y. (2015). Working with high risk, marginalized youth: Youth-led development of a framework of youth engagement. https://youthrex.com/report/working-withhigh-risk-marginalized-youth-youth-leddevelopment-of-a-framework-of-youthengagement
Iwasaki, Y., Dashora, P., McHugh, T.-L., McLaughlin, A.-M., \& Springett, J. (2016). Reflections on the opportunities and challenges of youth engagement: Youth and professional perspectives. Engaged Scholar Journal: Community-Engaged Research, Teaching, and Learning, 1(2). https://doi.org/10.15402/esj.v1i2.111

Jagosh, J., Macaulay, A. C., Pluye, P., Salsberg, J., Bush, P. L., Henderson, J., Sirett, E., Wong, G., Cargo, M., \& Herbert, C. P. (2012). Uncovering the benefits of participatory research: Implications of a realist review for health research and practice. The Milbank Quarterly, 90(2), 311-346. https://doi.org/10.1111/j.14680009.2012.00665.x

Kirmayer, L. J. (2012). Rethinking cultural competence. Transcultural Psychiatry. https://doi.org/10.1177/1363461512444673

Klinck, J., Cardinal, C., Edwards, K., Gibson, N., Bisanz, J., \& Da Costa, J. (2005). Mentoring programs for Aboriginal youth. Pimatisiwin, 3(2). https://teipuwhakahauaa.teraumatatini.com/ uploads/klinck/2005/1216_Klinck2005.pdf

LaVeaux, D., \& Christopher, S. (2009). Contextualizing CBPR: Key principles of CBPR meet the Indigenous research context. Pimatisiwin, 7(1), 1. https://www.ncbi.nlm.nih.gov/pmc/articles/ PMC2818123/pdf/nihms144307.pdf

Lofland, J., \& Lofland, L. H. (1995). Analyzing social settings: A guide to qualitative observation and analysis (3rd Ed. ed.). Wadsworth Publishing Company Belmont, CA.

Macaulay, A. C., Commanda, L. E., Freeman, W. L., \& Gibson, N. (1999). Participatory research maximises community and lay involvement. The BMJ, 319(7212), 774. https://doi.org/10.1136/bmj.319.7212.774

National Collaborating Centre for Aboriginal Health. (2009). Health inequalities and social determinants of Aboriginal peoples' health. NCCAH. Retrieved 2016.10.06 from http://www.nccahccnsa.ca/docs/social\%20determinates/NCC AH-loppie-Wien_report.pdf

National Collaborating Centre for Aboriginal Health. (2013). An overview of Aboriginal 
health in Canada. NCCAH. Retrieved 2016.09.29 from http://www.nccahccnsa.ca/Publications/Lists/Publications/Att achments/101/abororiginal_health_web.pdf

Paradies, Y. (2018). Racism and indigenous health. In Oxford research encyclopedia of global public health. Oxford University Press.

https://doi.org/10.1093/acrefore/978019063 2366.013.86

Patton, M. Q. (1990). Qualitative evaluation and research methods: Fourth edition. SAGE Publications, inc. https://doi.org/10.1002/nur.4770140111

Reilly, R. E., Doyle, J., Bretherton, D., Rowley, K. G., Harvey, J. L., Briggs, P., Charles, S., Calleja, J., Patten, R., \& Atkinson, V. (2008). Identifying psychosocial mediators of health amongst Indigenous Australians for the Heart Health Project. Ethnicity \& Health, 13(4), 351-373. https://doi.org/10.1080/1355785080190304 6

Salsberg, J., Parry, D., Pluye, P., Macridis, S., Herbert, C. P., \& Macaulay, A. C. (2015). Successful strategies to engage research partners for translating evidence into action in community health: A critical review. Journal of Environmental and Public Health, 2015. https://doi.org/10.1155/2015/191856

Sandelowski, M. (2000). Whatever happened to qualitative description? Research in Nursing \& Health, 23(4), 334-340. https://doi.org/10.1002/1098240X(200008)23:4\%3C334::AIDNUR9\%3E3.0.CO;2-G

Stewart, S., Riecken, T., Scott, T., Tanaka, M., \& Riecken, J. (2008, Mar). Expanding health literacy: Indigenous youth creating videos. Journal of Health Psychology, 13(2), 180-189. https://doi.org/10.1177/1359105307086709

United Nations. (2003). World youth report. http://www.un.org/esa/socdev/unyin/docum ents/ch04.pdf

Young, T. K., \& Chatwood, S. (2017). Delivering more equitable primary health care in Northern Canada. Canadian Medical Association Journal, 189(45), E1377.

https://doi.org/10.1503/cmaj.170498 


\section{Appendices}

\section{Appendix A}

\section{Characteristics of Community-Based Participatory Research in this Project}

\begin{tabular}{|c|c|}
\hline Study context & Alignment with CBPR characteristics \\
\hline Indigenous context & $\begin{array}{l}\text { - CBPR techniques have been shown to be particularly positive in } \\
\text { historically disenfranchised communities (Holkup et al., 2004) } \\
\text { CBPR can address the negative impacts of prior research by ensuring } \\
\text { community consultation, participation, and centrality of Indigenous } \\
\text { ways of knowing (Macaulay et al., 1999) that are imperative to this } \\
\text { project's epistemology } \\
\text { While CBPR does not guarantee cultural safety, it reminds us of the } \\
\text { importance of ongoing reflection in order to minimize any assault on } \\
\text { participants' cultural identity (Kirmayer, 2012) }\end{array}$ \\
\hline $\begin{array}{l}\text { Youth as end-users of this } \\
\text { research }\end{array}$ & $\begin{array}{l}\text { Participatory research has roots in the self-determination and } \\
\text { sovereignty movements of Canada's First Nations, united to "create } \\
\text { scientific knowledge with those who are most affected by the issue } \\
\text { being studied" (Cargo \& Mercer, 2008) } \\
\text { - Continued transparency of the research process with the youth } \\
\text { participants facilitates enhanced trust between the researchers and } \\
\text { communities (Ford et al., 2012) }\end{array}$ \\
\hline $\begin{array}{l}\text { Power relationships and } \\
\text { imbalances }\end{array}$ & $\begin{array}{l}\text { - CBPR as a framework takes into account the power imbalances that } \\
\text { have resulted from a long history of colonialism and forced } \\
\text { assimilation (LaVeaux \& Christopher, 2009) for Indigenous peoples } \\
\text { and populations } \\
\text { - Further power relations exist for Indigenous youth; current and } \\
\text { historical power relationships were continuously reflected upon, and } \\
\text { were discussed with participants }\end{array}$ \\
\hline $\begin{array}{l}\text { Overarching purpose to } \\
\text { inform CHB and IAMP } \\
\text { teams' decision-making } \\
\text { about healthier } \\
\text { communities }\end{array}$ & $\begin{array}{l}\text { - CBPR approaches aim to incorporate and honour community } \\
\text { members' priorities, ensuring the equitable inclusion of youth voices } \\
\text { in the development of policy and planning for healthier communities } \\
\text { (Graham et al., 2006) }\end{array}$ \\
\hline
\end{tabular}




\section{Appendix B}

Strategies Used for a Successful Participatory Research Partnership

\begin{tabular}{|l|l|}
\hline $\begin{array}{l}\text { 1) Memorandum of } \\
\text { Understanding (MOU) }\end{array}$ & $\begin{array}{l}\text { The pre-existing memorandum with the CHB was followed and } \\
\text { respected. It is worthy to highlight that the respect for Cree culture, } \\
\text { historical trauma, Cree ownership of data and confidentiality was } \\
\text { followed strictly according to the MOU and Institutional Review } \\
\text { Board Ethical guidelines. }\end{array}$ \\
\hline $\begin{array}{l}\text { 2) Use formal and informal } \\
\text { group facilitation techniques }\end{array}$ & $\begin{array}{l}\text { The focus group sessions were co-facilitated by the primary author } \\
\text { and a community partner who works at the local community school, } \\
\text { providing valuable contextual knowledge of local conditions for the } \\
\text { Nemaska youth. Informal techniques, such as opening the discussion } \\
\text { based on hobby sharing, and the primary author's frequent } \\
\text { community activity participation prior to the discussions, were used } \\
\text { as advised by our community partners. }\end{array}$ \\
\hline 3) Frequent communication & $\begin{array}{l}\text { Communication was maintained via frequent email, social media, and } \\
\text { text message exchange, as well as physical trips between Montreal } \\
\text { and Nemaska. }\end{array}$ \\
\hline
\end{tabular}




\section{Appendix C}

\section{Implications for Policy, Practice and Future Research}

To reach a more optimal level and capacity of youth engagement in health planning for the Eeyou Istchee, Cree participants in this study have suggested and recommended the following points of action:

- Create positions for youth to be health planners, to better the engagement, relevance, trust in, sustainability and promotion of the initiative.

- Create positions for youth to be health delegates, and to share knowledge of and promote existing CHB and other healthcare services in schools and in the community amongst youth groups.

- Highlight youth role models and include youth testimonials to capitalize on youth inspiring other youth.

- Incorporate a social media plan for youth communication, and continue to try and reach marginalized youth and solicit their particular needs.

- Continue to support and invest in all forms of engagement opportunities for youth, including participation, youth council membership, and health planning, in recognition of the interconnectedness between health and engagement for Cree youth.

- Implement regular and holistic evaluations of youth positions or programs, incorporating the use of qualitative research and testimonial evaluation methods in addition to other measures, such as attendance rates and outcomes, to better understand effective mechanisms for engagement and other implications in Eeyou Istchee. 